\title{
COMISSIONAMENTO DE PLANTA PILOTO DE PIRÓLISE UTILIZANDO REATOR DE LEITO FLUIDIZADO
}

\author{
Lucas M. Dianin*, Nahieh T. Miranda, Daniel S. Fernandes, Maria Regina W. Maciel.
}

\begin{abstract}
Resumo
Como uma forma de diminuir o consumo de combustíveis fósseis, a pirólise da biomassa tem sido uma das alternativas para produção de biocombustíveis, pela capacidade de produzir bio-óleo (combustível líquido - produto de maior interesse), biochar (carvão vegetal - sólido) e gases. Portanto, esse projeto tem como objetivo o comissionamento de um reator de leito fluidizado, presente em uma planta piloto de processos termoquímicos, para realizar pirólise rápida de bagaço de cana-de-açúcar, determinando as condições operacionais para produção de líquidos e sólidos.
\end{abstract}

\section{Palavras-chave:}

Pirólise, reator de leito fluidizado, planta piloto.

\section{Introdução}

Atualmente, há uma busca por fontes alternativas para suprir as crescentes necessidades energéticas. No Brasil, a cana-de-açúcar destaca-se, pelo País ser o maior produtor dessa commodity ${ }^{1}$, assim como o maior exportador de açúcar, e o maior produtor e consumidor de etanol de cana-de-açúcar do mundo, o que faz gerar uma quantidade excessiva de bagaço (173 milhões de toneladas na safra 2017/2018) ${ }^{2}$. Como uma forma de agregar valor a esse subproduto, o processo de pirólise rápida surge como uma alternativa, o qual degrada a biomassa por meio da transferência de calor $(500-600$ $\left.{ }^{\circ} \mathrm{C}\right)^{3}$ e de massa resultantes de um aquecimento rápido, com uma pequena ou nula porção de oxigênio, gerando gases $(13-20 \%)$, bio-óleo $(20$ - $75 \%)$ e biochar $(12$ $30 \%)^{4-6}$. Sendo assim, fazendo uso de uma planta piloto de processos termoquímicos, previamente utilizada para gaseificação na tese de doutorado de Figueroa $(2015)^{7}$, o objetivo do projeto foi determinar as condições operacionais (vazão do gás de fluidização, vazão de biomassa e temperatura do reator) de um reator de leito fluidizado para realizar pirólise rápida, avaliando a possibilidade de produção de bio-óleo e biochar.

\section{Resultados e Discussão}

O comissionamento da planta piloto incluiu etapas de instalação e adaptação: transferência da planta para um laboratório com saída de emergência; instalação hidráulica para alimentar os trocadores de calor; instalação elétrica do laboratório para energizar a planta; instalação do sistema de exaustão de gases, instalação das resistências elétricas de aquecimento e isolamento térmico (lã de vidro); e, detecção de vazamentos. Após o comissionamento da planta, realizaram-se os experimentos, os quais exigem que as resistências estejam nas temperaturas definidas previamente antes de os ensaios serem iniciados. Os resultados obtidos estão indicados na Tabela 1. Os baixos rendimentos de bio-óleo são resultados de uma troca de calor ineficiente por parte do trocador de calor presente no sistema da planta piloto (resultado importante que foi detectado na planta que foi adaptada de um gaseificador) que dificultou a condensação dos compostos pesados da corrente gasosa. Entretanto, apesar do baixo rendimento, é notável que a corrida 08 apresentou 0 melhor resultado, uma vez que as condições impostas no sistema promoveram a formação de 35,88 \% de biochar e 7,07 \% de bio-óleo (segundo maior rendimento).
Tabela 1. Condições operacionais e rendimentos dos produtos.

\begin{tabular}{|c|c|c|c|c|c|c|}
\hline Rodada & $\begin{array}{l}\text { Gás de } \\
\text { Fluidização }\end{array}$ & $\begin{array}{c}\text { Temperatura do } \\
\text { Reator }\left({ }^{\circ} \mathrm{C}\right)\end{array}$ & $\begin{array}{c}\text { Vazão Bagaço } \\
(\mathrm{kg} / \mathrm{h})\end{array}$ & $\begin{array}{l}\text { Vazão Gás } \\
\text { (L/min) }\end{array}$ & $\begin{array}{l}\text { Rendimento } \\
\text { Bio-óleo (\%) }\end{array}$ & $\begin{array}{l}\text { Rendimento } \\
\text { Biochar (\%) }\end{array}$ \\
\hline \multirow{2}{*}{1} & \multirow{2}{*}{$\mathrm{N}_{2}$} & \multirow{2}{*}{500} & 0,29 & \multirow{2}{*}{40} & 3,07 & \multirow{2}{*}{3,35} \\
\hline & & & 1,16 & & 1,00 & \\
\hline 2 & $A R$ & 500 & 2 & 40 & - & 19,66 \\
\hline 3 & AR & 500 & 2 & 40 & 0,27 & 20,83 \\
\hline 4 & $A R$ & 600 & 2 & 70 & 3,64 & 15,03 \\
\hline 5 & AR & 560 & 2 & 40 & 4,15 & 10,91 \\
\hline 6 & $A R$ & 600 & 2 & 40 & 0,09 & 10,28 \\
\hline 7 & AR & 600 & 2,7 & 26,16 & - & 9,24 \\
\hline 8 & $A R$ & $540-600$ & 3,1 & 28,26 & 7,07 & 35,88 \\
\hline 9 & AR & 500 & 3,5 & 29,92 & 4,05 & 30,13 \\
\hline 10 & $A R$ & 500 & 3,5 & 25,93 & 7,43 & 19,51 \\
\hline 11 & AR & 520 & 3,5 & 33,91 & 5,24 & 27,09 \\
\hline 12 & $A R$ & 600 & 2 & 20 & - & 13,42 \\
\hline
\end{tabular}

\section{Conclusões}

Os resultados obtidos mostram que para obtenção de alto rendimento de bio-óleo, modificações importantes devem ser feitas na planta piloto de pirólise (originada de um gaseificador). Já o rendimento de biochar, na maior parte das corridas, corresponde aos valores encontrados na literatura para pirólise rápida. Portanto, conclui-se que as condições operacionais utilizadas foram satisfatórias e mostrou que a metodologia de realizar pirólise rápida em uma planta piloto que antes realizava gaseificação foi de importância tecnológica para a área. Além disso, concluiu-se que seria recomendável substituir o trocador de calor casco e tubo simples por um trocador de calor com maior superfície de troca de calor.

\section{Agradecimentos}

Agradecimentos ao $\mathrm{PIBIC/CNPq}$, à FAPESP/CAPES \#2016/18546-8, \#2015/20630-4 e \#2017/18401-2 e ao CNPq.

\footnotetext{
${ }^{1}$ Lima, M. P. e Castro, M. C. G. Produção da cana-de-açúcar no Brasil uma análise dos impactos socioeconômicos da implantação do complexo sucroalcooleiro no município de Vicentinópolis. 2016.

${ }^{2}$ União da Indústria de Cana-de-Açúcar. UNICA. São Paulo. 2018

${ }^{3}$ Sohaib, Q.; Muhammad, A.; Younas, M. Fast pyrolysis of sugarcane bagasse: Effect of pyrolysis conditions on final product distribution and properties. Energy Sources, 39:2, 184-190. 2017.

${ }^{4}$ Madhu, P.; Livingston, T. S. e Kanagasabapathy. Flash Pyrolysis of Lemon Grass (Cymbopogon flexuosus) for Bio-oil Production in an Electrically Heated Fluidized Bed Reactor. 2017

5 Pérez, J. M. M.; Rocha, J. D.; Cortez, L. A. B. e Jordan, R. A. Fast pyrolysis as a percursor of BTL. São Paulo. Edgard Blücher. 2014, 733-740.

${ }^{6}$ Bridgwater, T. Biomass Pyrolysis. IEA Bioenergy T34200701, 1-20. 2007.

Figueroa, J. E. J. Procesos termoquímicos para processamento de bagaço de cana-de-açúcar: pirólise em leito fixo e gaseificação em leito fluidizado. 148f. Tese (Doutorado em Engenharia Química) - Faculdade de Engenharia Química, UNICAMP. 2015.
} 